ARTIKEL

\title{
PENGARUH STRES KERJA, KARAKTERISTIK INDIVIDU DAN KOMITMEN NORMATIF TERHADAP KINERJA KARYAWAN DI PT. EINS TREND FACTORY 2
}

\author{
${ }^{1}$ Nur Khalimah, ${ }^{2}$ Dedeng Abdul Gani Amruloh \\ 1,2STIE DR. KHEZ. Muttaqien \\ Email: Nurkhalimah502@gmail.com
}

\begin{abstract}
Abstrak
Penelitian ini bertujuan untuk mengetahui pengaruh stres kerja, karakteristik individu dan komitmen normatif terhadap kinerja karyawan pada PT. Eins Trend Factory 2 . Pada data yang dimiliki PT. Eins Trend Factory 2 terdapat informasi pencapaian kinerja yang kurang optimal, hal ini terlihat dari produksi yang tidak mencapai target produksi dan mengalami penurunan pencapaian target produksi setiap tahunnya. Metode yang digunakan dalam penelitian ini adalah kuantitatif dan pendekatan verifikatif dengan pengumpulan data melalui survei. Populasi dalam penelitian ini adalah karyawan yang bekerja di PT. Eins Trend Factory 2 sebanyak 83 responden, dengan nonprobability sampling dan teknik pengambilan sampel yang digunakan adalah purposive sampling. Analisis data dalam penelitian ini menggunakan analisis regresi linier berganda, uji t dan uji $\mathrm{F}$ dan uji determinasi. Hasil penelitian ini menunjukkan bahwa stres kerja berpengaruh negatif dan signifikan terhadap kinerja pegawai, variable karakteristik individu berpengaruh positif dan signifikan terhadap kinerja pegawai, sementara komitmen normatif berpengaruh positif dan signifikan terhadap kinerja pegawai, serta Stres kerja, karakteristik individu dan komitmen normatif berpengaruh positif dan signifikan terhadap kinerja pegawai.
\end{abstract}

Kata Kunci: Stres Kerja, Karakteristik Individu, Komitmen Normatif, Kinerja Karyawan.

\begin{abstract}
This study to research the effect of work stress, individual commitment and normative commitment to employee performance at PT. Eins Trend Factory 2. In the data held by PT. Eins Trend Factory 2 contains information that is missing performance that is less than optimal, this can be seen from the production that has not reached the production target and has decreased the production target every year. The method used in this research is quantitative and a verification approach with data through surveys. The population in this study were employees who worked at PT. Eins Trend Factory 2 as many as 83 respondents, with nonprobability sampling and the sampling technique used was purposive sampling. Analysis of the data in this study using multiple linear regression analysis, $t$ test and $F$ test and test of determination. The results showed that job stress has a negative and significant effect on employee performance, individual influence variables have a positive and significant effect on employee performance, while normative commitment has a positive and significant effect on employee performance, and job stress, individual relationships and normative commitment have a positive and significant effect. on employee performance.
\end{abstract}

Keywords : Work Stress, Individual Characteristics, Normative Commitment, Employee Performance. 


\section{A. PENDAHULUAN}

Sumber daya manusia merupakan kunci yang sangat penting dalam pertumbuhan dan perkembangan sebuah organisasi guna mencapai tujuannya. Maka perusahaan dituntut untuk dapat meningkatkan kualitas sumber daya manusia guna mencapai tujuan perusahaan (Cupian dkk, 2020; Mulyadi, 2020). Dalam mencapai tujuan, perusahaan mempunyai target dalam melaksanakan setiap kegiatan operasionalnya, karena itu setiap sumber daya manusia yang ada diharapkan memberikan hasil yang optimal bagi perusahaan (Ahmaddien \& Sa'dia, 2020).

Melihat tinggi atau rendahnya kualitas sumber daya manusia pada sebuah perusahaan, tingkat kinerja karyawan pada pencapaian suatu target yang telah ditetapkan perusahaan dapat dijadikan sebagai alat evaluasi untuk di masa depan (Ramadhiansah dkk, 2020; Wilis \& Wulandari, 2019). Menurut Hasibuan (2017) Kinerja adalah hasil kerja yang dicapai seseorang dalam melaksanakan tugas-tugas yang dibebankan kepadanya yang didasarkan atas kecakapan, inisiatif, pengalaman dan kesungguhan serta waktu.

PT. Eins Trend Merupakan salah satu perusahaan yang bergerak dibidang manufaktur yang berbentuk pakaian (garment), Perusahaan ini telah berdiri sejak januari 2005. PT. Eins Trend sendiri kini dibagi ke beberapa tempat produksi (factory), yaitu Factory 2, Factory 3 dan Factory 5. Dan setiap factory memiliki divisi masing-masing guna menunjang kegiatan produksi.

Tentunya semua perusahaan mempunyai target produksi yang harus dicapai oleh karyawan. Seperti pada PT. Eins Trend Factory 2 pada bagian atau departemen penjahitan (Sewing Department), karyawan dituntut untuk memenuhi jumlah (kuota) target produksi yang ditetapkan agar tidak berdampak pada peningkatan nilai biaya produksi (cost production). Apabila target produksi tidak tercapai, maka ada biaya lebih (overhead) yang harus dikeluarkan perusahaan (Melati \& Wulandari, 2019)..

Dari data yang dimiliki PT. Eins Trend khususnya Factory 2 pada sewing department terdapat informasi pencapaian kinerja yang kurang maksimal. Hal itu terlihat dari data produksi dalam rentang waktu 2017-2019, yaitu tidak tercapainya target produksi bahkan mengalami penurunan setiap tahunnya.

Berikut adalah data hasil produksi pada tahun 2017-2020 pada PT.Eins Trend factory 2 pada sewing department.

\section{Tabel 1}

Data Produksi Sewing Departement di PT. Eins Trend Factory 2

\begin{tabular}{lcccccc}
\hline Bulan & $\begin{array}{c}\text { Target } \\
\text { Produksi }\end{array}$ & $\begin{array}{l}\text { Actual } \\
\text { Output }\end{array}$ & $\begin{array}{c}\text { Target } \\
\text { Produksi }\end{array}$ & $\begin{array}{c}\text { Actual } \\
\text { Output }\end{array}$ & $\begin{array}{c}\text { Target } \\
\text { Produksi }\end{array}$ & $\begin{array}{c}\text { Actual } \\
\text { Output }\end{array}$ \\
\cline { 2 - 7 } & $\mathbf{2 0 1 7}$ & $\mathbf{2 0 1 7}$ & $\mathbf{2 0 1 8}$ & $\mathbf{2 0 1 8}$ & $\mathbf{2 0 1 9}$ & $\mathbf{2 0 1 9}$ \\
Januari & 769.291 & 738.519 & 605.493 & 575.218 & 523.737 & 497.550 \\
Februari & 529.603 & 508.419 & 616.004 & 585.204 & 1.014 .838 & 964.096 \\
Maret & 465.187 & 446.580 & 717.755 & 681.867 & 575.803 & 547.013 \\
April & 629.876 & 604.681 & 840.163 & 798.155 & 507.879 & 482.485 \\
Mei & 879.798 & 844.606 & 722.842 & 686.700 & 821.705 & 780.619 \\
Juni & 700.402 & 672.386 & 430.603 & 409.073 & 511.965 & 486.367 \\
Juli & 683.482 & 656.143 & 601.819 & 571.728 & 624.152 & 592.945 \\
Agustus & 756.977 & 726.698 & 1.012 .837 & 962.195 & 354.213 & 336.503 \\
\hline
\end{tabular}


ARTIKEL

\begin{tabular}{lrrrrrr}
\hline September & 459.718 & 441.329 & 656.667 & 623.834 & 1.038 .911 & 986.965 \\
Oktober & 619.836 & 595.043 & 542.896 & 515.751 & 5233.737 & 497.550 \\
November & 799.071 & 767.108 & 764.910 & 726.665 & 647.691 & 615.306 \\
Desember & 1.204 .591 & 1.156 .408 & 910.967 & 865.418 & 1.181 .618 & 1.122 .537 \\
TOTAL & $\mathbf{8 . 4 9 7 . 8 3 2}$ & $\mathbf{8 . 1 5 7 . 9 2 0}$ & $\mathbf{8 . 4 2 2 . 9 5 6}$ & $\mathbf{8 . 0 0 1 . 8 0 8}$ & $\mathbf{8 . 3 2 6 . 2 4 9}$ & $\mathbf{7 . 9 0 9 . 9 3 6}$ \\
\hline
\end{tabular}

Sumber : Data Produksi PT Einstrend 2020

Dari tabel 1 mengenai Data Produksi PT. Eins Trend Factory 2 pada Sewing Department, menunjukan bahwa target produksi tahun 2017 yang telah ditetapkan oleh perusahaan yaitu sebesar 8.497.832 Pcs garment namun pada kenyataannya hasil produksi hanya mencapai sebesar 8.157.920 Pcs garment hal ini masih jauh dari target yang telah ditetapkan oleh perusahaan, begitu juga pada tahun 2018 dengan target produksi 8.422.956 Pcs garment yang hanya mampu mencapai produksi sebesar 8.001.808 Pcs garment.

Hal ini juga terjadi di tahun 2019, perusahaan belum mampu menaikan jumlah produksinya terbukti dari hasil produksi di tahun 2019 yaitu sebesar 7.909.936 Pcs garment dari yang ditargetkan perusahaan yaitu sebesar 8.326.249 Pcs garment. Hal tersebut menandakan kinerja karyawan di PT. Eins Trend Factory 2 pada Sewing Department belum berjalan secara maksimal.

Setelah mengetahui kinerja karyawan, ada beberapa variabel yang dapat mempengaruhi kinerja karyawan salah satunya adalah stres kerja Hasibuan (2017:204) menyatakan tingkat stres yang tinggi dapat menurunkan kinerja karyawan, kinerja karyawan yang stres pada umumnya dapat menurun karena mengalami ketegangan pikiran. Menurut (Zainal et al., 2017:308) stres kerja Adalah adanya kondisi ketidakseimbangan yang timbul karena tuntutan lingkungan dan tanggapan setiap individu yang dalam menyikapinya berbeda dan dapat terjadi pada semua kondisi pekerjaan.

Di PT. Eins Trend Factory 2 pada Sewing Department sendiri ditemukan salah satu penyebab stres kerja yaitu, beban kerja yang terlalu tinggi yang dirasakan oleh karyawan karena harus mencapai output produksi yang tinggi dengan waktu yang terbatas dengan tuntutan kualitas produksi harus sempurna. Rata-rata karyawan belum mampu melaksanakan tanggung jawabnya dengan baik sehingga mengakibatkan banyaknya permasalahan dalam kegiatan produksinya seperti banyaknya kualitas yang belum sesuai dengan kriteria ataupun standar yang telah ditetapkan oleh perusahaan hal lain yang terjadi seperti seringnya overtime dikarenakan tidak tercapainya target yang telah ditentukan oleh perusahaan, hal ini mengakibatkan karyawan mudah merasa lelah dan menjadi lengah dalam melakukan pekerjaannya. Tabel dibawah ini menunjukan hasil kualitas barang yang telah diproduksi pada tahun 2019.

Tabel 2

Data Kualitas Produksi

\begin{tabular}{lrrrr}
\hline Bulan & $\begin{array}{c}\text { Defect } \\
\text { Quantity }\end{array}$ & Total Accept & $\begin{array}{c}\text { Total } \\
\text { Quantity }\end{array}$ & Defect (\%) \\
\hline Januari & 7.942 & 738.519 & 746.461 & 1.01 \\
Februari & 7.220 & 508.419 & 515.639 & 1.40 \\
Maret & 8.360 & 446.580 & 454.940 & 1.83 \\
April & 9.120 & 604.681 & 613.801 & 1.48 \\
\hline
\end{tabular}


ARTIKEL

\begin{tabular}{lrrrr}
\hline Mei & 9.975 & 844.606 & 854.581 & 0.01 \\
Juni & 6.156 & 672.386 & 678.542 & 0.90 \\
Juli & 13.110 & 656.143 & 669.253 & 1.95 \\
Agustus & 12.958 & 726.698 & 739.656 & 1.75 \\
September & 13.167 & 441.329 & 454.496 & 2.89 \\
Oktober & 19.665 & 595.043 & 614.708 & 3.19 \\
November & 23.940 & 767.108 & 791.048 & 3.02 \\
Desember & 38.703 & 1.156 .408 & 1.195 .111 & 3.23 \\
TOTAL & $\mathbf{1 7 0 . 3 1 6}$ & $\mathbf{8 . 1 5 7 . 9 2 0}$ & $\mathbf{8 . 3 2 8 . 2 3 6}$ & $\mathbf{2 . 0 5}$ \\
\hline
\end{tabular}

Sumber : olah data pra survey 2020

Dari tabel 2 mengenai Data Kualitas Produksi PT. Eins Trend Factory 2 pada Sewing Department, menunjukan bahwa ada masalah pada kualitas barang dan terus meningkat setiap bulannya, tentunya hal ini akan menghambat kegiatan produksi karena banyak barang yang harus dipermak (perbaikan kualitas), apabila hal ini terjadi secara terus menerus perusahaan akan mengalami kerugian dikarenakan harus mengeluarkan biaya dan waktu lebih guna melakukan perbaikan pada kualitas produksi dan tidak menutup kemungkinan hasil output kualitasnya tidak sebagus dengan output lainnya, hal ini juga dapat berpengaruh pada penilaian buyer (pembeli) yang mungkin akan mengurangi pemberian order ke perusahaan tersebut. Untuk itu perusahaan harus mengetahui apa penyebab karyawan tersebut mengalami stres kerja. Guna mengurangi masalah yang mungkin dapat berdampak negatif terhadap kegiatan produksinya.

Terlepas dari stres kerja, karakteristik individu juga mempengaruhi kondisi psikologis seseorang dalam melakukan kegiatan operasional dalam perusahaan. Didalam sebuah perusahaan tentunya memiliki beragam karakteristik pada sumber daya manusianya. Perbedaan karakteristik individu ini akan mempengaruhi kegiatan operasional perusahaan yang dapat berdampak pada tujuan sebuah organisasi $(\mathrm{Tj}, 2020)$.

Menurut Thoha (2012:35) Karakteristik individu merupakan pandangan, tujuan, kebutuhan dan kemampuan yang berbeda satu sama lain dari setiap orang. Karakteritik seseorang merupakan pembeda kepribadian yang dimilikinya termasuk menjadi wirausahawan (Amruloh, 2019:123). Perbedaan ini akan terbawa dalam dunia kerja, yang akan menyebabkan kepuasan satu orang dengan yang lain berbeda pula, meskipun bekerja ditempat yang sama. Karakteristik individu yang baik akan menjadikan karyawan tersebut lebih mudah dalam melaksanakan pekerjannya, sehingga kinerja yang dihasilkan akan lebih optimal. Begitupun sebaliknya, apabila karyawan mempunyai karakteristik yang buruk, dapat menghambat operasional perusahaan dan dapat menyebabkan kinerja yang dihasilkan kurang optimal.

Pada kenyataannya karakteristik individu di PT. Eins Trend Factory 2 pada Sewing Department karyawan masih kurang semangat dalam menjalankan tanggung jawab atau tugasnya, yang disebabkan oleh beberapa hal yaitu tingkat pendidikan yang rendah, mental yang lemah, kurangnya pengalaman kerja serta sikap karyawan yang masih kurang baik karena masih bermalas-malasan hal ini ditunjukan dengan banyaknya karyawan yang tidak masuk kerja dengan berbagai macam alasan. Dalam kasus ini perusahaan harus selalu memberikan motivasi atau 
ARTIKEL

perhatian bagi karyawannya. Agar karyawan mempunyai minat dalam melaksanakan tanggung jawabnya.

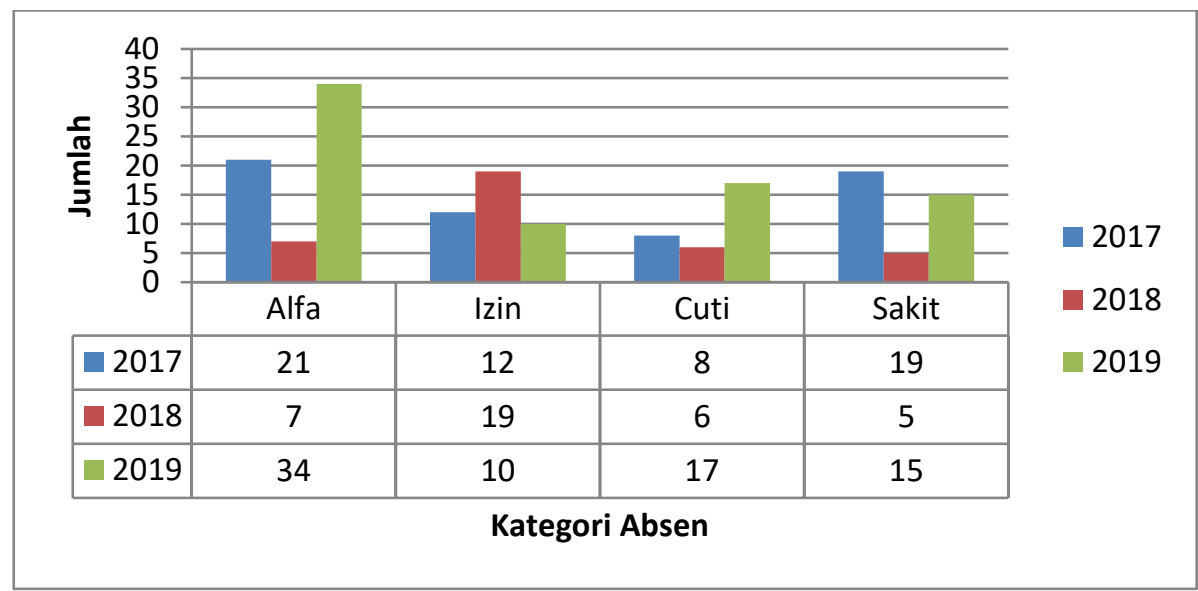

Sumber: Hrd PT Eins Trend

\section{Grafik 1}

Data Absensi Sewing Departemens PT Eins Trend Factory 2

Di dalam PT. Eins Trend sendiri setiap karyawan mempunyai tugas masing-masing yang harus mereka kerjakan, Dari grafik 1 di atas menunjukan bahwa dalam setiap tahun ada karyawan yang tidak dapat masuk kerja dengan berbagai alasan, pada tahun 2017 dapat dilihat bahwa karyawan yang tidak masuk kerja tanpa keterangan (alfa) sebanyak 21 orang, izin 12 orang, cuti 8 orang dan sakit sebanyak 19 orang. Pada tahun 2018 mengalami perubahan, jumlah karyawan yang tidak masuk kerja mengalami penurunan dengan karyawan yang tidak masuk kerja dengan alasan tanpa keterangan (alfa) sebanyak 7 orang, izin 19 orang, cuti 6 orang dan sakit sebanyak 5 orang. Akan tetapi pada tahun 2019 dapat kita lihat bahwa pada tahun ini justru mengalami kenaikan dari 2 tahun sebelumnya dengan jumlah karyawan yang tidak masuk kerja tanpa keterangan (alfa) sebanyak 34 orang, izin 10 orang, cuti sebanyak 17 orang dan sakit sabanyak 15 orang.

Selanjutnya Kuatnya komitmen dari seorang karyawan pada perusahaan turut menjadi penentu bagaimana sifat dan tingkah laku karyawan tersebut selama berada dalam perusahaan. Ketika karyawan merasa puas dengan apa yang ada didalam perusahaan, maka mereka akan memberikan kontribusi yang optimal bagi perusahaannya. Karyawan yang memiliki komitmen yang tinggi terhadap perusahaan cenderung akan menunjukkan kualitas yang baik.

Menurut Robbins (2015:101) individu yang mampu meningkatkan kinerja adalah individu yang memiliki komitmen tinggi terhadap pekerjaanya dan tempat dimana dia bekerja dan individu tersebut akan memberikan kontribusi yang besar terhadap kemajuan, pertumbuhan dan berkembangnya sebuah organisasi atau perusahaan. Menurut (Khaerul Umam, 2012) komitmen normatif menggambarkan perasaan keterikatan untuk terus berada dalam organisasi.

Pada kenyataannya di PT. Eins Trend Factory 2 pada Sewing Department seringkali karyawan keluar dari perusahaan karena berbagai macam hal seperti perusahaan belum mampu memberikan kontribusi yang optimal, tidak ada kepastian kontrak kerja, hal dilihat dari perusahaan 
ARTIKEL

tidak mampu mengangkat karyawan kontrak menjadi karyawan tetap dan karyawan hanya diberikan perjanjian kerja selama kurang lebih satu tahun oleh pihak perusahaan untuk menuntut karyawan tersebut agar berkomitmen dalam menyelesaikan perjanjian kerja.

Apabila kontrak kerja sudah berakhir biasanya perusahaan akan memberikan perjanjian atau kontrak kedua agar karyawan tetap bertahan di perusahaan. Hal ini menjadikan karyawan tidak memiliki perasaan untuk tetap loyal terhadap perusahaan karena perusahaan sendiri tidak memberikan hak yang sesuai dengan apa yang diinginkan oleh karyawan, sehingga banyak karyawan yang memilih untuk tidak melanjutkan kontrak kedua dan memilih untuk meninggalkan perusahaan, karena merasa tidak ada jenjang karir yang pasti yang dapat diberikan oleh perusahaan kepadanya.

Fenomena komitmen normatif karyawan di Eins Trend Factory 2 pada Sewing Department ditunjukan dengan banyaknya jumlah karyawan yang keluar dari perusahan yang meningkat setiap tahunnya. Hal ini dapat ditunjukan pada Grafik 2.

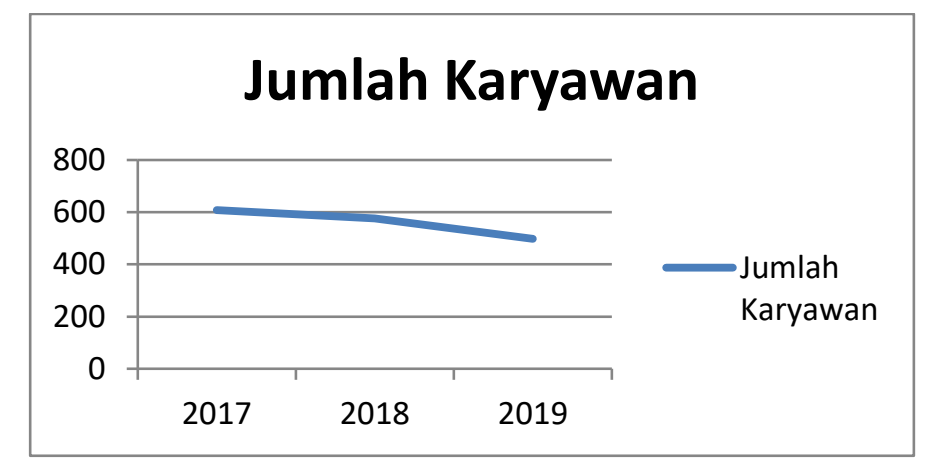

Sumber: Data jumlah karyawan PT Eins Trend 2020

Grafik 2

Jumlah Karyawan PT Eins Trend 2020

Pada grafik 2 diatas dapat dilihat bahwa jumlah karyawan mengalami penurunan setiap tahunnya, dapat dilihat pada tahun 2017 jumlah karyawan di PT. Eins Trend Factory 2 pada sewing Department mempunyai karyawan sejumlah 608 orang, namun pada tahun 2018 jumlah karyawan berkurang menjadi 576 orang, ditahun 2019 juga tidak ada perubahan dalam perusahaan karyawan dikarenakan jumlah karyawan menjadi berkurang lagi menjadi total 498 orang. Hal ini tentunya dapat sangat menganggu kegiatan operasional karyawan yang dikarenakan kurangnya jumlah karyawan dalam perusahaan tersebut.

Berdasarkan latar belakang di atas maka masalah dalam penelitian ini dirumuskan sebagai berikut : bagaimana pengaruh stress kerja, karakteristik individu dan komitmen normatif terhadap kinerja karyawan Di PT. Eins Trend, baik secara parsial maupun simultan. 


\section{B. KAJIAN PUSTAKA}

\section{Kinerja Karyawan}

Pengertian kinerja (prestasi kerja) adalah hasil kerja secara kualitas dan kuantitas yang dicapai oleh seorang pegawai dalam melaksanakan tugasnya sesuai dengan tanggung jawab yang diberikan kepadanya Mangkunegara (2017:67). Menurut Hasibuan (2017:94) Kinerja adalah suatu hasil kerja yang dicapai seseorang dalam melaksanakan tugas yang dibebankan kepadanya yang didasarkan atas kecakapan, pengalaman dan kesungguhan serta waktu.

\section{Stres Kerja}

Stres kerja adalah perasaan tertekan yang dialami karyawan dalam menghadapi pekerjaan Mangkunegara (2017:157). Menurut Hasibuan (2017:204), stres kerja adalah suatu kondisi ketegangan yang mempengaruhi emosi, proses berfikir, dan kondisi seseorang.

\section{Karakteristik Individu}

Menurut Mathis (2012:64) karakteristik individu adalah ciri khas atau sifat khusus yang dimiliki seseorang karyawan yang dapat menjadikan dirinya memiliki kemampuan yang berbeda dengan orang lain untuk mempertahankan dan memperbaiki kerja di dalam organisasinya. Sedangkan Menurut Arief Subyantoro (2014:11-19) menyebutkan bahwa setiap orang mempunyai pandangan, tujuan, kebutuhan, dan kemampuan yang berbeda satu sama lain. Perbedaan ini akan terbawa dalam dunia kerja, yang akan menyebabkan kepuasan satu orang dengan yang lain berbeda pula, meskipun bekerja ditempat yang sama.

\section{Komitmen Normatif}

Menurut Wibowo (2016:188) mengemukakan bahwa komitmen pada dasarnya merupakan kesediaan seseorang untuk mengikatkan diri dan menunjukan loyalitas pada organisasi karena merasakan dirinya terlibat dalam kegiatan organisasi. Menurut (Khaerul Umam, 2012) Normative Commitment, menggambarkan perasaan keterikatan untuk terus berada dalam organisasi.

\section{METODE PENELITIAN}

Metode yang digunakan dalam penelitian ini adalah kuantitatif dengan menggunakan metode deskriptif dan verifikatif dengan pengumpulan data melalui survei. Populasi dalam penelitian ini adalah karyawan yang bekerja di PT. Eins Trend Factory 2 sejumlah 83 responden, dengan teknik pengambilan sample Nonprobability sample, dan untuk teknik sampling yang digunakan yaitu Purposive Sampling. Analisis data dalam penelitian ini adalah uji validitas dan reliabilitas, uji asumsi klasik, serta analisis regresi linear berganda, uji t dan uji $F$ dan uji determinasi.

\section{HASIL DAN PEMBAHASAN}

Sebelum melihat Apakah pengaruh stres kerja, karakteristik individu dan komitmen normatif terhadap kinerja karyawan di PT. Eins Trend factory 2 pada sewing department terlebih dahulu dilakukan uji validitas dan reabilitas terhadap kuesioner yang diberikan kepada responden. Tujuan pengujian validitas dan reabilitas adalah untuk meyakinkan bahwa kuesioner yang disusun 
ARTIKEL

benar-benar layak dan baik dalam mengukur gejala dan menghasilkan data yang valid untuk digunakan dalam penelitian.

\section{Pengujian Hipotesis Secara Parsial (Uji t)}

Uji t atau uji parsial dilakukan untuk mengetahui masing-masing variabel independen mempunyai pengaruh atau tidak terhadap variabel dependen dan selanjutnya dapat diketahui variabel independen yang dominan berpengaruh terhadap variabel terikat dengan $\alpha=0.05$ pada tingkat kepercayaan 95\%. Tabel berikut adalah hasil dari Uji t yang dilakukan pada penelitian ini:

Tabel 3

Hasil Uji t

\begin{tabular}{|c|c|c|c|c|c|c|}
\hline & & & Coefficientsa & & & \\
\hline & & Unstan & rdized & Standardized & & \\
\hline & & $\mathrm{B}$ & Std. Error & Beta & & \\
\hline 1 & (Constant) & 16.912 & 4.264 & & 3.966 & .000 \\
\hline & Stres Kerja & -.094 & .045 & -.161 & -2.098 & .039 \\
\hline & $\begin{array}{l}\text { Karakteristik } \\
\text { Individu }\end{array}$ & .661 & .119 & .539 & 5.551 & .000 \\
\hline & Komitmen Normatif & .326 & .133 & .133 & 2.443 & .017 \\
\hline
\end{tabular}

Sumber:data diolah peneliti 2020

a. Stres kerja

Berdasarkan tabel 3, diatas menunjukan stres kerja diperoleh thitung sebesar -2,098 dan ttabel 1,66437 (df=79) dengan nilai signifikansi 0,039.

Karena thitung nilai t negatif maka menggunakan nilai t mutlak, atau t hitung $=2,098$, dimana $|-2,098|=|2,098|$ :

Sehingga perbandingan $t_{\text {hitung }}>\mathrm{t}_{\text {tabel menjadi } 2,098}>1,66437$, serta signifikansi lebih kecil dari 0,05 $(0,039>0,05)$, maka hipotesis $\left(\mathrm{H}_{1}\right)$ yang menyatakan bahwa stres kerja berpengaruh signifikan terhadap kinerja karyawan di PT.Eins Trend factory 2 pada sewing department diterima. Sehingga dapat disimpulkan ada pengaruh secara signifikan antara Stres Kerja terhadap Kinerja Karyawan.

b. Karakteristik Individu

Berdasarkan tabel 3, diatas dapat diketahui karakteristik individu diperoleh thitung sebesar 5,551 dan ttabel 1,66437 dengan nilai signifikansi 0,00. Karena thitung $>$ ttabel $(5,551>1,66437)$, dengan signifikansi lebih kecil dari 0,05 $(0,00>0,05)$, maka hipotesis $\left(\mathrm{H}_{2}\right)$ yang menyatakan bahwa stres kerja berpengaruh signifikan terhadap kinerja karyawan di PT.Eins Trend factory 2 pada sewing department diterima. Sehingga dapat disimpulkan ada pengaruh secara signifikan antara Karakteristik Individu terhadap Kinerja Karyawan.

c. Komitmen Normatif

Berdasarkan tabel 3 diatas dapat diketahui komitmen normatif diperoleh thitung sebesar 2,443 dan ttabel 1,66437 dengan nilai signifikansi 0,17. Karena $t_{\text {hitung }}>t_{\text {tabel }}$ 
ARTIKEL

$(2,443>1,66437)$, dan signifikansi lebih kecil dari $0,05(0,21>0,05)$, maka hipotesis $\left(\mathrm{H}_{3}\right)$ yang menyatakan bahwa komitmen normatif berpengaruh signifikan terhadap kinerja karyawan di PT.Eins Trend factory 2 pada sewing department diterima. Sehingga dapat disimpulkan ada pengaruh secara signifikan antara Komitmen Normatif terhadap Kinerja Karyawan.

\section{Pengujian Hipotesis Secara Simultan (Uji F)}

Uji $F$ atau uji serentak yaitu untuk melihat bagaimanakah pengaruh seluruh variabel independen secara simultan atau bersama-sama terhadap variabel dependen. Dengan $\alpha=0.05$ pada tingkat kepercayaan $95 \%$. Hasil uji F yang dilakukan pada penelitian ini tampak pada tabel 11 berikut:

Tabel 4

Hasil Uji F

\begin{tabular}{|l|l|r|r|r|r|r|}
\hline \multicolumn{7}{|l|}{ ANOVAa } \\
\hline \multicolumn{1}{|l|}{ Model } & Sum of Squares & \multicolumn{1}{c|}{ Df } & Mean Square & F & Sig. \\
\hline \multirow{7}{*}{1} & Regression & 2713.187 & 3 & 904.396 & 33.995 & $.000^{\mathrm{b}}$ \\
\cline { 2 - 7 } & Residual & 2101.680 & 79 & 26.604 & & \\
\cline { 2 - 7 } & Total & 4814.867 & 82 & & & \\
\hline
\end{tabular}

Sumber: Data diolah dalam penelitian 2020

Berdasarkan tabel 4 diketahui bahwa stres kerja, karakteristik individu, komitmen normatif, berpengaruh secara simultan dan signifikan terhadap perilaku konsumen dengan taraf signifikansi 0,05 . Dengan melihat nilai signifikansi $0,000<0,05$, maka dengan demikian hipotesis $\left(\mathrm{H}_{4}\right)$ yang menyatakan bahwa "stres kerja, karakteristik individu, dan komitmen normatif berpengaruh secara signifikan terhadap kinerja karyawan di PT.Eins Trend factory 2 pada sewing departement" diterima. Sehingga dapat disimpulkan secara simultan Stres Kerja $\left(\mathrm{X}_{1}\right)$, Karakteristik Individu $\left(\mathrm{X}_{2}\right)$ dan Komitmen Normatif $\left(\mathrm{X}_{3}\right)$ berpengaruh terhadap Kinerja Karyawan(Y).

\section{Uji Determinasi}

Koefisien Determinasi $\left(\mathrm{r}^{2}\right)$ dimaksudkan untuk mengukur kemampuan seberapa besar presentase variabel independen pada model regresi berganda dalam menjelaskan variabel dependen. Berikut adalah tabel 5 hasil perhitungan koefisien determinasi dari penelitian ini:

Tabel 5

Hasil Uji Determinasi

\begin{tabular}{|l|l|r|r|r|}
\hline \multicolumn{5}{|c|}{ Model Summary } \\
\hline Model & \multicolumn{1}{|c|}{ R } & R Square & \multicolumn{1}{c|}{ Adjuster R Square } & Std. Error of the estimate \\
\hline 1 & $.751^{\mathrm{a}}$ & .564 & .547 & 515.786 \\
\hline a. Predictors: (Constant), Stres Kerja, Karakteristik Individu, Motivasi \\
\hline
\end{tabular}

Sumber: data diolah dalam penelitian 2020

Berdasarkan tabel 5 di atas, diperoleh nilai R square sebesar 0,564 (56,4\%). Hal ini berarti bahwa 56,4\% variabel dependen kinerja karyawan dijelaskan oleh variabel stres kerja, 
ARTIKEL

karakteristik individu, komitmen normatif. Sisanya sebesar 43,6\% dijelaskan oleh variabel lain yang tidak termasuk dalam penelitian ini.

\section{E. KESIMPULAN}

Berdasarkan hasil penelitian, dapat disimpulkan bahwa stres kerja berpengaruh negatif terhadap kinerja karyawan. Hal ini menunjukan bahwa semakin tinggi stres kerja maka semakin menurun kinerja karyawan. Variabel karakteristik individu juga terbukti berpengaruh positif terhadap kinerja karyawan. Hal ini menunjukan semakin tinggi karakteristik individu maka semakin meningkat kinerja karyawan. Sementara Variabel komitmen normatif berpengaruh positif terhadap kinerja karyawan Hal ini menunjukan semakin tinggi komitmen normatif maka semakin meningkat kinerja karyawan Stres kerja, karakteristik individu dan komitmen normatif secara bersama-sama atau simultan berpengaruh positif terhadap kinerja karyawan.

\section{DAFTAR PUSTAKA}

Amruloh, D. A. G. (2019). Kajian Filosofis Karakteristik Wirausaha Urang Sunda. Eqien: Jurnal Ekonomi dan Bisnis, 6(2), 119-130.

Hasibuan Malayu S.P. (2017). Manajemen Sumber Daya Manusia. Jakarta: PT. Bumi Aksara. Mangkunegara, Anwar Prabu. (2017). Manajemen Sumber Daya Manusia Perusahaan. Bandung : PT. Remaja Rosdakarya.

Mathis, Robert L. Dan John H. Jackson. (2012). Manajemen Sumber Daya Manusia. Edisi Pertama. Jakarta : Salemba Empat.

Sahid Raharjo. (2018, Februari). www.spssindonesia.com. Retrieved from https://www.spssindonesia.com/2018/02/cara-menghitung-se-sr-regresi-berganda.html

Stephen, Robbins. (2015). Perilaku Organisasi. Jakarta : Salemba Empat.

Subiyantoro Arief . (2014). Manajemen Sumber Daya Manusia, Edisi Kedua. Yogyakarta: STIE YKPN.

Sugiyono. (2017). Metode Penelitian Kuantitatif, Kualitatif, Dan R\&D. Bandung : Alfabeta, CV. Sugiyono. (2018). Metode Penelitian Manajemen. Bandung : Alfabeta, CV.

Thoha, M. (2012). Kepemimpinan Dalam Manajemen. Jakarta : PT. Raja Grafindo Persada. Umam, Khaerul. (2012). Perilaku Organisasi. Cetakan Kedua. Bandung : Pustaka Setia. Wibowo. (2016). Manajemen Kinerja. Edisi Kelima. Jakarta: PT. Raja Grafindo Persada.

Wiyono, Gendro. (2011). Merancang Penelitian Bisnis Dengan Alat Analisis SPSS 17.0 Dan Smartpls 2.0. Yogyakarta: UPP STIM YKPN.

Zainal, V., R Hadad, M. D., \& Ramly, M. (2017). Kepemimpinan Dan Perilaku Organisasi. Jakarta : PT Rajagrafindo Persada.

Cupian, C., Zaky, M., Nurjaman, K., \& Kurnia, E. (2020). Analisis Pelaksanaan Rekruitmen, Seleksi Dan Penempatan Berdasarkan Perspektif Islamic Human Capital. Komitmen: Jurnal Ilmiah Manajemen, 1(1), 50-63.

Ahmaddien, I., \& Sa'dia, N. H. (2020). Pengaruh Kebijakan Upah Minimum Terhadap Penyerapan Tenaga Kerja Perempuan Di Indonesia. Komitmen: Jurnal Ilmiah Manajemen, 1(1), 22-32. 
ARTIKEL

Ramadhiansah, I., Agustin, I. C., Fauzi, H., Majid, H. A., Nurzaini, H., \& Suhaemi, B. (2020). PENGARUH BUDAYA ORGANISASI TERHADAP KINERJA KARYAWAN (Studi pada Karyawan Bank BRI Kantor Cabang Cianjur). AKSELERASI: Jurnal Ilmiah Nasional, 2(3), 44-55.

Mulyadi, D. (2020). The Influence of the Role of Leadership and Compensation on Employee Performance of PT Taiho Nusantara. International Journal of Science and Society, 2(4), 480-491.

Tj, H. W. (2020). The Impact of Organizational Culture on Public Service Employee Success in Bandung City. ENDLESS: International Journal of Future Studies, 3(1), 48-54.

Wilis, R. A., \& Nurwulandari, A. (2020). The effect of E-Service Quality, E-Trust, Price and Brand Image Towards E-Satisfaction and Its Impact on E-Loyalty of Traveloka's Customer. Jurnal Ilmiah MEA (Manajemen, Ekonomi, \& Akuntansi), 4(3), 1061-1099.

Melati, M., \& Nurwulandari, A. (2019). Analisis Reaksi Pasar terhadap Stock Split pada Perusahaan Bertumbuh dan Tidak Bertumbuh. Oikonomia: Jurnal Manajemen, 13(2). 